\title{
Analysis of Peach Germplasm in Mexico
}

\author{
S. Pérez, S. Montes, and C. Mejía \\ Instituto National de Investigaciones Forestales y Agropecuarias (INIFAP)-Región Centro, A.P. 112, \\ Celaya, Gto., 38000, Mexico
}

Additional index words. morphology, phenology, principal component analysis, Prunus persica

\begin{abstract}
A wide range of peach [ Prunus persica (I,.) Batsch] germplasm was collected from the most important peach growing regions in Mexico and some Latin American countries, as well as from breeding programs in the United States, Europe, and South Africa. Budded trees, seedlings derived from selfing cultivars and selections, and seed samples from various growing regions were propagated and planted in central Mexico. Twenty eight morphological or phenological variables were recorded on 52 accessions representing different geographic regions. The highest degree of variability was observed for traits related to bud density and distribution, and to phenological variables associated with temperature requirements such as budbreak and harvest seasons, leaf fall, fruit development, and seed stratification period. Principal component analysis (PCA) integrated groups of phenotypes based mainly on growth habit, shoot diameter, bud and leaf size, as well as resistance to powdery mildew, rust, and frost. PCA provides support for the development of objectives and breeding strategies in the search for germplasm and cultivars for nontraditional peach growing regions.
\end{abstract}

Peaches were introduced in Mexico early in the 16th century and were rapidly spread throughout all temperate regions. After $>100$ generations of sexual reproduction, they have adapted to a wide range of ecological conditions, from Papantla, Veracruz, where they grow side by side with vanilla and bananas, up to the coldest regions in the north, where they survive in winter at $-12 \mathrm{C}$. Presently, the peach is the most important temperate fruit species cultivated in central and southern Mexico due to its wide distribution and high local demand (Perez, 1989).

During the last 3 decades, peach plantings in Mexico have increased from 13,000 to 42,000 ha. Peach production is based mainly on seedling trees $(60 \%)$. local selections $(15 \%)$, and cultivars introduced from the United States (Perez, 1989). Seedling orchards are generally heterogeneous because they come from seed mixtures of unknown genetic origin (Perez, 1990a). but in some regions they constitute relatively uniform populations due to selection, as in the main growing regions (Zacatecas and Michoacan) or even in smaller populations such as the evergreen 'Tetela' in Morelos and 'Tancítaro' in Michoacan.

Introduced cultivars are mainly melting freestones from U.S. breeding programs that have become important because they extend the harvest season (Diaz et al., 1986). However, they are less firm and have a different flavor than peaches demanded by the local market. These characteristics present transportation and commercialization problems, especially in central Mexico.

Local and introduced germplasm could be the basis for the genetic improvement of the species in Mexico to solve some of the most limiting factors for local peach production, such as susceptibility to powdery mildew, poor tree structure. frosts, and short harvest season. However, information available about this peach germplasm is limited. Descriptions include mainly freestone cultivars generated by U.S. breeding programs (Bellini and Scaramuzzi, 1976; Della Strada et al., 1984) or derived from a similar genetic base (Fideghelli et al., 1991; Okie et al., 1985; Scorza et al., 1988). Even though these studies consider a wide range of cultivars, relationships among them are based only on pedigree records. Associations among variables and among cultivars and/or populations, especially in relation to other germplasm sources, need to be

Received for publication 24 Apr. 1992. Accepted for publication 19 Oct. 1992. The cost of publishing this paper was defrayed in part by the payment of page charges. Under postal regulations, this paper therefore must be hereby marked advertisement solely to indicate this fact. considered. Studies including a wider range of germplasm could provide a better perspective and understanding for future peach breeding programs. Furthermore, due to the relatively narrow genetic base of the world's leading freestone peach cultivars (Okie et al., 1985; Scorza et al., 1985; Scorza et al., 1988), it becomes important to describe and use alternate genetic resources that may contribute to integrating genomes and widening world peach production areas or to increasing efficiency in traditional peach growing regions (Callahan et al., 1991; Hough, 1985; Monet, 1988; Scorza, 1985; Scorza and Okie, 1990).

The use of multivariate analysis for germplasm description and characterization has been useful to explain speciation and domestication in annual species (Martin and Adams, 1987; Montez, 1989) and to study genetic and morphological relationships in sour cherries (Hilling and Iezzoni, 1988) and apricots (Perez, 1992a). This approach could allow a wider perspective to evaluate diverse germplasm sources that could be used in future breeding programs.

The main objectives of this work were: 1) to describe and compare a wide range of peach germplasm outside the main peach growing regions, and 2) to detect associations among variables and among genotypes to establish a solid base for peach breeding in central Mexico.

\section{Materials and Methods}

This work was initiated in 1985 with the collection of buds and/ or seed samples derived from selling cultivars and selections from important peach growing regions in central and southern Mexico, as well as from Guatemala, Bolivia, Brazil, southern Europe, South Africa, and the United States (Tables 1 and 2). Fifty-two accessions were used for this study: 10 of the most important peach cultivars currently grown in central Mexico (five budded trees of each cultivar); 28 families (each with a minimum of 20 seedlings) derived either from selfing introduced cultivars or selections (15), or selfing local selections (13); and 14 seed samples (populations)

Abbreviations: BB, budbreak season; $\mathrm{Bd}$, bud diameter; $\mathrm{Bn}$, buds per node: $\mathrm{B} / \mathrm{sl}$, buds per meter: Co, color; DS, defoliation season; Fdp, fruit development period; Firm, flesh firmness; Frw, fruit weight; Fl/sl, flower density; Fw : pw, flesh to pit weight ratio; $\mathrm{GH}$, growth habit; GP, germination period; HS, harvest season; La, leaf area; NW, nodes with zero buds: N1 b, nodes with one bud; N2b. nodes with two buds; N3b. nodes with three buds; P, productivity; PCA, principal component analysis: Prec. precocity; pw, pit weight, Rf, resistance to frost; RSp, resistance to powdery mildew: RTd, resistance to rust; sd, shoot diameter. 
collected from the main peach growing regions in Mexico and three Latin American countries. The trees were planted in Mar. 1985 and 1986 using a completely randomized design in a semiarid region under irrigation in northern Guanajuato (elevation $2000 \mathrm{~m}$; 450 to $550 \mathrm{~h}$ of chilling) at $4 \times 3 \mathrm{~m}$ spacing. They were given standard cultural practices with minimal pruning and thinning to allow natural growth habit expression.

From 1987 to 1989, 28 variables were recorded (Table 3) as described:

1) Vigor: was determined by using trunk diameter and height data during the first three growing seasons; we used a scale where 1 = weak or stunted and $5=$ highly vigorous.

2) Growth habit $(\mathrm{GH})$ : based on a scale from 1 = bushy vigorous (i.e. evergreens) to $5=$ an erect and more desirable tree shape.

3) Leaf area (La) in square centimeters based on a random sample collected from the tree canopy and consisting of 20 young fully expanded leaves. Area of individual leaves was measured with an electronic meter (Delta T; Decagon Devices, Pullman, Wash.).

4 to 6) Degree of resistance to powdery mildew (Sphaeretoco pannosa (Wallr.) Lév, RSp), rust (Tranzchelia discolor (Fckl.) Tranz. \& Livt., RTd), and frost (Rf), using a scale from $1=$ highly susceptible to $5=$ highly resistant.

7) Budbreak season (BB): from $1=$ extremely early (November) as registered for the lowest chilling requirement cultivar ('Okinawa'), to $10=$ very late (late March to early April) such as 'Calanda'.

8) Precocity (Prec): crop load during the 2nd and 3rd leaf from $0=$ none to $5=$ very high.

9) Bud diameter $(\mathrm{Bd})$ : diameter of 15 buds as recorded with a hand-held calliper, from $1=\operatorname{small}(1 \mathrm{~mm})$ to $4=$ large $(4 \mathrm{~mm})$.

The following data were taken on fifteen 1 -year-old shoots per accession randomly sampled around the tree canopy at a height of 1.5 to $2 \mathrm{~m}$.

10 to 11) Bud density: based on the average number of buds per shoot length before budbreak and expressed as the number of buds per meter $(\mathrm{B} / \mathrm{sl})$ and as the number of buds per node $(\mathrm{Bn})$.

12 to 15) Bud distribution as the proportion of nodes with three $(\% \mathrm{~N} 3 b)$, two $(\% \mathrm{~N} 2 b)$, one $(\% \mathrm{~N} 1 \mathrm{~b})$, and zero buds $(\% \mathrm{~N} 0 \mathrm{~b})$, i.e., number of nodes with three buds/total number of nodes per shoot length $\times 100$.

16) Flower density (Fl/sl), average number of flowers per shoot length: flowers/meter.

17) Shoot diameter $(\mathrm{Sd})$ : average diameter measured at $2 \mathrm{~cm}$ above the base of the shoots.

Table 1. List of introduced peach cultivars and families studied.

\begin{tabular}{llll}
\hline \hline Cultivars & Origin & Families & Origin \\
\hline Chiripa & Brazil & Bolivia & Bolivia \\
CNF1 & México-USA & Calanda & Spain \\
Diamante & Brazil & Fertit & Greece \\
EarliGrande & Texas & Guatemala & Quetzaltenago \\
FlordaGrande & Texas-Florida & ISF-1 & Italia \\
Flordagold & Florida & Kakamas & Sud Africa \\
Flordaprince & Florida & N2-10 & México-USA \\
Lucero & México & Neethling & Sud Africa \\
Magno & Brazil & Nemaguard & California \\
Springcrest & California & NJ8514 & New Jersey \\
& & NJ8557 & New Jersey \\
& & Okinawa & Japan \\
& & USDA-N & California \\
& & Zarcha & Pakistan \\
\hline
\end{tabular}

18) Productivity $(\mathrm{P})$ : based on a scale from $1=$ none to $5=$ extremely high.

19) Harvest season (HS): based on a 2-week interval, from extremely early ( $\mathrm{HS}=1$, mid-May) to very late $(\mathrm{HS}=10$, early October).

20) Fruit development period (Fdp): number of days from bloom to harvest.

On 20-fruit samples, five variables were recorded:

21) Fruit weight (Frw): average fruit weight in grams without thinning.

22) Color (Co): $1=$ red epidermis and white flesh; $2=$ white flesh and epidermis; 3 = red epidermis and yellow flesh; and $4=$ yellow flesh and epidermis.

23) Flesh firmness (Firm), reflecting approximate values registered with the penetrometer in $\mathrm{kg} \cdot \mathrm{cm}^{2}$ from $1=1 \mathrm{~kg} \cdot \mathrm{cm}^{2}$ to $8=$ $8 \mathrm{~kg} \cdot \mathrm{cm}^{2}$.

24) Flesh to pit weight ratio (Fw : pw).

25) Pit weight $(\mathrm{Pw})$ : average pit weight in grams.

26) Defoliation season (DS): time when trees had lost $90 \%$ of their leaves based on a 2 -week interval from $1=$ very early (September) to $5=$ very late (November).

Using 50 seeds per accession (five replications with 10 seeds each), we determined:

27) Number of days required to reach $80 \%$ germination under stratification at $6 \mathrm{C}(\mathrm{D} 80 \mathrm{~g})$.

28) Germination period (GP): number of days from the first seed germinated to $80 \%$ germination.

Mean values registered for each variable were used to perform a PCA (Crisci and Lopez, 1983: Iezzoni and Pritts, 1991) to detect possible associations among variables and among cultivars, families, and populations.

\section{Results and Discussion}

Characteristics. The most vigorous trees were the seedlings of evergreen peaches (Table 3). such as 'Tetela' or related forms such as 's174' and 's100'. The least vigorous were some seedlings derived from selfing semidwarf selections from Italy (ISFl) and 'Flordagold', or the stunted seedlings of 'Oradea', 'Fertit', and 'Zarcha' from colder regions, which had poor budbreak and yield due to insufficient chilling accumulation.

GH based on tree shape and shoot density along the main branches was useful to separate local from introduced genotypes (Table 3). Most of the Latin American populations have an open

Table 2. List of Mexican selections and populations studied.

\begin{tabular}{lclc}
\hline $\begin{array}{l}\text { Selfed } \\
\text { selections }\end{array}$ & $\begin{array}{c}\text { Altitude } \\
(\mathrm{m})^{2}\end{array}$ & Populations & $\begin{array}{c}\text { Altitude } \\
(\mathrm{m})\end{array}$ \\
\hline s82 & 2100 & Altotonga & $24(\mathbf{k})$ \\
s100 & 2000 & Guzmán & 2100 \\
s174 & 2050 & Jalacingo & 2450 \\
s195 & 1950 & Loreto & 2100 \\
I5-2 & 1850 & Puebla & 2100 \\
I5-9 & 1900 & Sinaloa & 2000 \\
I8-16 & 2200 & Solana & 1800 \\
I8-26 & 2300 & Tancítaro & 1900 \\
I9-26 & 1900 & Tequila & 1900 \\
II2-6 & 1950 & Tetela & 2000 \\
II2-12 & 2000 & Ucareo & 2300 \\
III5-34 & 2100 & Zacatecas 2 & 2200 \\
Canario & 2050 & Zahutla & 2300
\end{tabular}

$\overline{{ }^{\prime} \text { Refers to elevation above sea level from where germplasm was obtained. }}$ 


\begin{tabular}{|c|c|c|c|c|c|c|c|c|c|c|c|c|c|c|c|c|c|c|c|c|c|c|c|c|c|c|c|c|}
\hline Accession Vi & figor & GH & 1.9 & $\mathrm{RSp}$ & RTd & $\mathbf{R f}$ & $\mathrm{BB}$ & Ptec & $\begin{array}{c}\mathrm{Bd} \\
(\mathrm{mm})\end{array}$ & $\begin{array}{c}B / s I \\
(n / m)\end{array}$ & $\mathrm{B} / \mathrm{n}$ & $\begin{array}{l}\mathrm{N}(\mathrm{lb} \\
(\%)\end{array}$ & $\begin{array}{l}\text { Nib } \\
(\%)\end{array}$ & $\begin{array}{l}\mathrm{N} 2 \mathrm{~h} \\
(\%)\end{array}$ & $\begin{array}{l}\text { N.3b } \\
\{\%\rangle\end{array}$ & $\begin{array}{l}\mathrm{F} \cdot \mathrm{l} / \mathrm{s} \mid \\
(\mathrm{n} / \mathrm{m})\end{array}$ & $\begin{array}{c}\text { Su } \\
\text { (mm) }\end{array}$ & $\mathbf{P}$ & HS & $\begin{array}{c}\text { Fdp } \\
\text { (days) }\end{array}$ & $\begin{array}{l}\text { Frw } \\
(g)\end{array}$ & Co & Firm & $\mathrm{Fw} / \mathrm{pw}$ & $\begin{array}{l}P_{w} \\
(g)\end{array}$ & DS & $\begin{array}{l}\text { D80g } \\
\text { (days) }\end{array}$ & $\begin{array}{c}\text { Gp } \\
\text { (days) }\end{array}$ \\
\hline Chirpa & 3 & 3.5 & 2 & 3 & 1 & 3 & 5 & 4 & 3 & 120 & 1.70 & 10.0 & 32.0 & 20.0 & 38.0 & 40 & 4 & 4 & 4 & 150 & 120 & 1 & 2 & 20 & 4 & 2 & 70 & 30 \\
\hline CNF1 & 4 & 3.5 & 3 & 3 & 1 & 4 & 4 & 2 & 3 & 108 & 1.90 & 7.0 & 32.8 & 19.8 & 8.9 & 57 & 4 & 4 & 5 & 150 & 130 & 3 & 8 & 25 & 5 & 1 & 60 & 20 \\
\hline Diamante & 4 & 2.5 & 2 & 4 & 2 & 2 & 0 & 4 & 2 & 118 & 1.44 & 5.4 & 62.0 & 15.2 & 7.4 & 61 & 3 & 5 & 0 & 110 & 90 & 4 & 4 & 20 & 3 & 3 & 50 & 30 \\
\hline EarliGrande & 4 & 4.0 & 3 & 3 & 1 & 4 & 2 & 3 & 3 & 100 & 1.78 & 8.5 & 54.5 & 12.3 & 24.6 & 59 & 4 & 4 & 0 & 80 & 100 & 3 & 1 & 25 & 4 & 1 & & \\
\hline Flordagold & 3 & 3.5 & 3 & 3 & 1 & 3 & 2 & 5 & 3 & 158 & 2.25 & 3.3 & 26.0 & 13.8 & 6.9 & 86 & 4 & 5 & 0 & 90 & 100 & 3 & 2 & 20 & 3 & 1 & 58 & 30 \\
\hline Flordagrande & $=4$ & 3.0 & 3 & 4 & 2 & 2 & 0 & 2 & 2 & 125 & 1.66 & 7.4 & 46.8 & 18.7 & 26.7 & 57 & 3 & 4 & 1 & 120 & 110 & 3 & 1 & 20 & 3 & 1 & 40 & 20 \\
\hline Hordaprince & 4 & 3.0 & 2 & 3 & 1 & 2 & 1 & 4 & 2 & 121 & 1.84 & 3.4 & 46.6 & 9.0 & 41.0 & 57 & 3 & 4 & u & 80 & 80 & 3 & 1 & 20 & 3 & 1 & 45 & 30 \\
\hline Lucero & 3 & 3.0 & 2 & 3 & 2 & 3 & 8 & 2 & 2 & 59 & 0.98 & 25.5 & 62.9 & 3.0 & 8.0 & 46 & 3 & 2 & 3 & 120 & 120 & 4 & 8 & 30 & 3 & 3 & 65 & 40 \\
\hline Magno & 4 & 3.5 & 2 & 4 & 1 & 4 & 4 & 5 & 2 & 118 & 1.51 & 12.1 & 35.6 & 17.2 & 35.0 & 34 & 4 & 5 & 3 & 140 & 120 & 3 & 6 & 20 & 4 & 2 & 50 & 30 \\
\hline Sprincrest & 4 & 4.0 & 3 & 3 & 1 & 4 & 9 & 3 & 3 & 90 & 1.55 & 14.8 & 37.0 & 25.3 & 21.1 & 37 & 4 & 4 & 0 & 90 & 110 & 3 & 1 & 25 & 3 & 1 & & \\
\hline Altotonga & 4 & 3.0 & 3 & 2 & 2 & 4 & 7 & 3 & 3 & 117 & 1.86 & 16.6 & 33.1 & 7.6 & 42.7 & 55 & 3 & 3 & 6 & 150 & 120 & 3 & 4 & 25 & 4 & 3 & 60) & 20 \\
\hline Canario & 4 & 2.0 & 1 & 2 & 2 & 3 & 7 & 4 & 2 & 111 & 1.70 & 14.7 & 30.1 & 29.9 & 24.9 & 53 & 2 & 4 & 7 & 180 & (x) & 3 & 8 & 20 & 3 & 4 & 6.5 & 10 \\
\hline Guzman & 4 & 2.0 & 1 & 2 & 2 & 3 & 6 & 3 & 2 & 162 & 2.17 & 5.5 & 30.1 & 17.1 & 47.2 & 2.3 & 2 & 3 & 7 & 170 & 80 & 3 & 4 & 20 & 3 & 3 & 55 & 20 \\
\hline IS-2 & 3 & 2.0 & 2 & 3 & 2 & 3 & 5 & 2 & 2 & 40 & 1.10 & 25.0 & 59.2 & 7.4 & 3.0 & 27 & 3 & 2 & 3 & 120 & 120 & 4 & 8 & 35 & 3 & 3 & 6.5 & 35 \\
\hline $15-9$ & 4 & 2.0 & 1 & 2 & 2 & 3 & 6 & 3 & 2 & 117 & 1.72 & 4.7 & 48.9 & 17.9 & 28.2 & 91 & 2 & 3 & 8 & $160)$ & 100 & 3 & 7 & 30 & 3 & 4 & 55 & 20 \\
\hline $18-16$ & 3 & 3.0 & 2 & 2 & 3 & 4 & 9 & 3 & 2 & 116 & 1.60 & 12.5 & 35.7 & 17.3 & 31.6 & 33 & 3 & 3 & 9 & 180 & 1.30 & 3 & 8 & 25 & 3 & 4 & 75 & 20 \\
\hline $18-26$ & 4 & 2.0 & 1 & 2 & 3 & 4 & 9 & 3 & 1 & 130 & 1.69 & 11.1 & 41.4 & 18.8 & 27.9 & 38 & 2 & 3 & 9 & 180 & 70 & 3 & 1 & 15 & 2 & 4 & 80 & 15 \\
\hline $19-26$ & 4 & 2.0 & 2 & 2 & 2 & 3 & 7 & 3 & 2 & 117 & 1.90 & 4.4 & 48.4 & 17.7 & 28.3 & 91 & 2 & 4 & 7 & 160 & 100 & 4 & 6 & 25 & 3 & 4 & 60 & 20) \\
\hline II2-6 & 4 & 20 & 1 & 2 & 2 & 3 & 7 & 4 & 2 & 143 & 2.11 & 2.6 & 32.0 & 17.3 & 47.9 & 34 & 2 & 3 & 7 & 170 & 80 & 3 & 4 & 15 & 2 & 3 & 60 & 10 \\
\hline II2-12 & 4 & 2.0 & 1 & 2 & 2 & 3 & 7 & 4 & 2 & 118 & 1.77 & 8.9 & 53.8 & 16.4 & 22.1 & 40 & 2 & 3 & 7 & 170 & 100 & 3 & 4 & 15 & 2 & 3 & 60 & 10 \\
\hline III5-.34 & 4 & 2.0 & 2 & 2 & 3 & 3 & 7 & 4 & 2 & 144 & 2.05 & 12.1 & 46.6 & 16.3 & 25.7 & 60 & 2 & 5 & 6 & 150 & 100 & 3 & 8 & 25 & 3 & 4 & 60 & 10 \\
\hline Jalacingo & 5 & 1.0 & 1 & 2 & 2 & 2 & 6 & 4 & 2 & 105 & 1.59 & 5.5 & 43.2 & 16.9 & 25.4 & 43 & 2 & 4 & 7 & 160 & 90 & 1 & 1 & 15 & 2 & 3 & 55 & 10 \\
\hline Loreto & 4 & 2.0 & 1 & 2 & 2 & 3 & 7 & 3 & 2 & 78 & 1.59 & 13.1 & 57.0 & 16.5 & 13.2 & 37 & 2 & 2 & 7 & 160 & 80 & 2 & 8 & 20 & 3 & 3 & 65 & 10 \\
\hline Pueblja & 4 & 2.0 & 1 & 2 & 2 & 3 & 6 & 3 & 2 & 103 & 1.46 & 6.5 & 57.9 & 18.1 & 16.8 & 45 & 2 & 3 & 7 & 160 & 90 & 3 & 6 & 25 & 3 & 3 & 55 & 15 \\
\hline S82 & 4 & 2.0 & 1 & 2 & 3 & 3 & 7 & 4 & 2 & 87 & 1.75 & 7.2 & 4.5 .4 & 17.3 & 31.9 & 62 & 2 & 4 & 8 & 160 & 90 & 3 & 8 & 20 & 2 & 3 & 60 & 10 \\
\hline$\$ 100$ & 5 & 1.5 & 1 & 2 & 3 & 2 & 8 & 2 & 1 & 150 & 2.11 & 3.0 & 27.5 & 12.1 & 57.3 & 70 & 2 & 4 & 6 & $160)$ & 100 & 4 & 8 & 25 & 3 & 4 & 60 & 10 \\
\hline$\$ 174$ & 5 & 1.5 & 1 & 2 & 3 & 2 & 6 & 4 & 2 & 141 & 2.109 & 9.4 & 34.3 & 21.0 & 34.1 & 64 & 2 & 4 & 6 & 170 & 100 & 4 & 8 & 25 & 3 & 4 & 55 & 10 \\
\hline S195 & 4 & 2.0 & 1 & 2 & 2 & 3 & 7 & 4 & 2 & 88 & 1.70 & 11.9 & 62.5 & 8.9 & 18.5 & 73 & 2 & 4 & 5 & 160 & 90 & 4 & 8 & 20 & 3 & 4 & 60 & 10 \\
\hline Sinaloa & 4 & 2.5 & 2 & 2 & 2 & 3 & 6 & 3 & 2 & 130 & 1.67 & 0.8 & 44.2 & 13.8 & 210 & 34 & 3 & 2 & 0 & 150 & 80 & 4 & 8 & 20 & 3 & 3 & 55 & 15 \\
\hline Solana & 4 & 2.0 & 1 & 2 & 2 & 2 & 6 & 3 & 2 & 70 & 1.69 & 4.3 & 48.9 & 17.1 & 20.6 & 48 & 2 & 3 & 6 & 150 & 90 & 4 & 8 & 25 & 3 & 3 & 50 & 20 \\
\hline Tancitaro & 4 & 1.5 & 1 & 2 & 3 & 1 & 4 & 4 & 2 & 165 & 1.66 & 2.2 & 53.8 & 18.0 & 26.0 & 55 & 2 & 4 & 6 & 150 & $(x)$ & 3 & 8 & 25 & 3 & 5 & 50 & 15 \\
\hline Tequila & 4 & 2.0 & 1 & 2 & 2 & 2 & 6 & 3 & 2 & 150 & 1.64 & 0.8 & 44.2 & 13.8 & 21.6 & 38 & 2 & 3 & 7 & 170 & 80 & 3 & 4 & 20 & 3 & 3 & 55 & 20 \\
\hline Tetcla & 5 & 1.0 & 1 & 2 & 3 & 1 & 5 & 1 & 1 & 74 & $1 .(0)$ & 16.8 & 49.8 & 10.1 & 24.3 & 43 & 2 & 3 & 6 & 160 & 90 & 2 & 6 & 25 & 2 & 5 & 50 & 15 \\
\hline Tuxtla & 4 & 2.0 & 1 & 2 & 2 & 3 & 6 & 3 & 2 & 97 & 1.74 & 8.6 & 45.5 & 21.2 & 24.9 & 33 & 2 & 3 & 7 & 170 & 90 & 3 & 6 & 20 & 3 & 3 & 55 & 20 \\
\hline Ucareo & 4 & 2.0 & 1 & 2 & 2 & 2 & 6 & 3 & 2 & 114 & 1.76 & 9.5 & 37.3 & 15.3 & 37.8 & 45 & 2 & 3 & 6 & 160 & 90 & 4 & 8 & 25 & 3 & 3 & 55 & 20 \\
\hline $\mathrm{Zac}$ & 4 & 2.0 & 1 & 2 & 2 & 2 & 7 & 4 & 2 & 104 & 1.73 & 4.4 & 59.4 & 19.3 & 14.8 & 38 & 2 & 4 & 8 & 170 & 80 & 4 & 8 & 25 & 3 & 4 & 60 & 10 \\
\hline Zahutla & 4 & 2.0 & 1 & 2 & 2 & 2 & 5 & 3 & 2 & 139 & 1.45 & 0.8 & 40.4 & 24.1 & 34.5 & 39 & 2 & 2 & 7 & 160 & 80 & 3 & 6 & 20 & 3 & 3 & 50 & 15 \\
\hline Bolivia & 4 & 2.0 & 2 & 2 & 2 & 2 & 6 & 3 & 2 & 104 & 1.66 & 9.8 & 49.2 & 14.1 & 26.2 & 68 & 2 & 3 & 9 & 190 & 90 & 3 & 7 & 25 & 3 & 4 & 55 & 10 \\
\hline Calanda & 4 & 3.0 & 3 & 2 & 3 & 3 & 9 & 2 & 2 & 83 & 1.41 & 17.8 & 4.3 .1 & 18.6 & 22.1 & 35 & 3 & 3 & 9 & 180 & 120 & 3 & 8 & 25 & 5 & 4 & 85 & 20 \\
\hline Fertit & 2 & 4.0 & 3 & 2 & 1 & 4 & 10 & 0 & 4 & 122 & 1.69 & 28.0 & 27.8 & 8.6 & 35.0 & 19 & 4 & 1 & 4 & 150 & 90 & 3 & 2 & 20 & 4 & 3 & 90 & 20 \\
\hline Guatemala & 4 & 3.0 & 2 & 2 & 2 & 2 & 6 & 3 & 2 & 141 & 2.01 & 3.9 & 20.4 & 20.5 & 55.5 & 82 & 2 & 3 & 6 & 160 & 90 & 3 & 6 & 25 & 3 & 3 & 55 & 20 \\
\hline ISF-I & 2 & 4.0 & 3 & 2 & 1 & 3 & 2 & 3 & 3 & 123 & 1.97 & 14.2 & 26.9 & 12.3 & 45.8 & 85 & 3 & 3 & 1 & 110 & 90 & 3 & 1 & 15 & 3 & 0 & 55 & 40 \\
\hline Kakamas & 3 & 2.0 & 3 & 3 & 2 & 2 & 6 & 2 & 2 & 51 & 0.81 & 24.9 & 73.6 & 0.0 & 3.0 & 28 & 3 & 2 & 5 & 140 & 110 & 4 & 8 & 30 & 3 & 3 & 60 & 30 \\
\hline N2-10 & 4 & 3.0 & 3 & 4 & 1 & 3 & 0 & 4 & 2 & 95 & 1.12 & 28.1 & 49.9 & 3.4 & 18.4 & 47 & 3 & 4 & 1 & 100 & 70 & 3 & 2 & 15 & 2 & 3 & 40 & 10 \\
\hline Neethling & 3 & 20 & 3 & 3 & 2 & 2 & 7 & 2 & 2 & 54 & 0.72 & 31.4 & 66.4 & 1.9 & 0.0 & 39 & 3 & 2 & 4 & 120 & 120 & 4 & 7 & 35 & 3 & 3 & 80 & 30 \\
\hline Nemaguard & 3 & 3.0 & 2 & 4 & 2 & 4 & 9 & 1 & 2 & 93 & 1.69 & 13.7 & 43.6 & 17.1 & 25.6 & 53 & 3 & 2 & 6 & 140 & 40 & 2 & 1 & 10 & 3 & 2 & 80 & 15 \\
\hline NJ8514 & 4 & 3.0 & 3 & 3 & 1 & 3 & 4 & 3 & 2 & 110 & 1.90 & 4.2 & 41.2 & 10.4 & 44.0 & 69 & 3 & 3 & 4 & 120 & 100 & 3 & 2 & 25 & 4 & 2 & 60 & 40 \\
\hline NJ8557 & 3 & 3.0 & 3 & 3 & 1 & 3 & 7 & 4 & 2 & 74 & 1.32 & 14.6 & 54.6 & 14.0 & 16.7 & 58 & 3 & 4 & 4 & 110 & 130 & 3 & 5 & 30 & 3 & 2 & 65 & 40 \\
\hline Okinawa & 4 & 3.0 & 2 & 4 & 2 & 2 & 7 & 4 & 2 & 92 & 2.04 & 1.7 & 47.2 & 14.0 & 36.8 & 63 & 2 & 4 & 3 & 120 & 80 & 1 & 1 & 20 & 2 & 2 & 35 & 10 \\
\hline Oradea & 2 & 4.0 & 4 & 2 & 1 & 4 & 10 & 0 & 4 & 82 & 1.25 & 23.5 & 54.0 & 9.9 & 13.0 & 14 & 4 & 1 & 4 & 140 & 80 & 2 & 3 & 20 & 3 & 3 & 90 & 20) \\
\hline USDA-F & 3 & 3.0 & 3 & 2 & 1 & 4 & 7 & 1 & 3 & 91 & 1.87 & 13.9 & 27.4 & 15.8 & 42.8 & 36 & 3 & 2 & 4 & 120 & 90 & 3 & 1 & 20 & 3 & 1 & 70 & 30 \\
\hline Zarcha & 2 & 30 & 3 & 2 & 2 & 4 & 10 & 1 & $?$ & 104 & 195 & 88 & 26.5 & 23.9 & 417 & 23 & 3 & i & $h$ & 140 & 100 & 2 & 4 & $2 n$ & 4 & 3 & 90 & 20 \\
\hline
\end{tabular}

"See list of abbreviations on the first page of this article.

shape with thin shoots. This characteristic gives them a bushy appearance, especially visible on the evergreen types. The breakpoint for $\mathrm{Sd}$ is $\approx 3 \mathrm{~mm}$, with $<3 \mathrm{~mm}$ for most local unselected seedling populations and $>3 \mathrm{~mm}$ for all cultivars, either local or introduced. Generally, Bd and La followed a similar trend, with cultivars and local selections exhibiting higher values than seedling trees collected from local populations.

Bud densities along I -year-old shoots were $>100 \mathrm{~B} / \mathrm{s} 1$ or $1.5 \mathrm{Bn}$ for most local populations (Table 3); these values are similar to those reported for cultivars from colder regions (Perez, 1992b), while the phenotypes from regions with Mediterranean climates had $<80$ buds $/ \mathrm{m}$ or less than one bud per node.

The proportion of nodes without buds (\%NOb) was $>25 \%$ in South African cultivars such as 'Neethling' and 'Kakamas', and in the seedlings derived from them, 15-2 and 'Lucero' (Table 3), reflecting a genetic origin for this trait (Perez, 1992b). The proportion of nodes without buds was also high for high chilling requirement families such as 'Fertit' and 'Oradea'. which were probably suffering from a lack of acclimation to local conditions. In general, bud distribution was skewed toward a higher proportion of buds per node, i.e., $\% \mathrm{~N} 2 \mathrm{~b}$ and $\% \mathrm{~N} 3 \mathrm{~b}$ vs. $\% \mathrm{~N} 1 \mathrm{~b}$ in local populations and cultivars introduced from Florida and Brazil; the cultivars collected from Mediterranean climates such as 'Calanda' exhibited the highest proportion of nodes with one bud.

RSp was relatively low in all Latin American seedling populations (Table 3). The highest degree of resistance was observed in some introduced cultivars such as 'Diamante' and 'Magno' from Brazil, as well as in 'FlordaGrande' from Florida and N2-10 (an open pollinated seedling nectarine locally selected from 'Sunred'). However, for rust, most local seedling populations were more 
resistant than introduced cultivars, with the evergreen types showing the highest resistance.

BB exhibited a wide range, with introduced families or cultivars located at both extremes (Table 3). For example. 'Okinawa' and N2-10 generally were in full bloom by late November, while 'Zarcha' and 'Oradea' were very late (early spring). Local populations and cultivars show intermediate BB between mid-February and mid-March.

Fl/sl along 1 -year-old shoots was higher than 50/m for almost all accessions, except for South African and Mediterranean cultivars (Table 3). A similar observation has been reported for these cultivars under a different environment (Perez, 1992b).

Most introduced cultivars had a shorter fdp ( $>130$ days) than local populations and selections (130 to 200 days) and had a HS between mid-May and mid-July ( $\mathrm{HS}=0$ to 4 in Table 3 ). The first Latin American populations started ripening by mid-July and the last ones early in October ( $\mathrm{HS}=6$ to 10 ). Some populations collected from frost free regions are generally harvested in December and January ('Tetela') and in early spring ('Tancitaro') in their places of origin. In northern Guanajuato, they were harvested in August along with most local selections.

Local populations were highly precocious, with the exception of 'Tetela'; under optimum conditions, the seedlings could reach 1.8 to $2 \mathrm{~m}$ in height after 1 year in the field and bloom during their second leaf, producing up to 120 fruits per tree $(\operatorname{Prec}=5$ in Table $3)$.

Tree Rf was low for the evergreens during the first two winters, as well as in some populations, such as 'Tancitaro', collected from frost free regions (Table 3). Lows of about $-8 \mathrm{C}$ are common early in the morning in northern Guanajuato. Even though these seedlings have most of their aerial parts killed during their first winter in the field, they generally are able to recover and become strong trees, larger, and longer lived than most standard peach trees. Hardier seedlings were collected from northern regions and were introduced from Europe or from the U.S. Most low chilling requirement genotypes derived from breeding programs in northem latitudes (Floridaand Italy) will easily survive winter temperatures at the end of their first year in the field if they are in rest. However, generally only their first and second bloom is able to ripen under normal winter temperatures. In later years, they bloom in early winter and rarely bear a crop. Higher chilling requirement genotypes, either local or introduced, do not present any problems with low winter temperatures; but if chilling accumulation in Guanajuato is bellow average, blossoms and yield are very poor.

Productivity $(\mathrm{P})$ was high for low chilling requirement families and cultivars in years without low winter temperatures (Table 3).

Frw was generally low (70 to $130 \mathrm{~g}$ ) for all accessions under the

Table 4. Eigenvalues and proportion of total variability among peach genotypes grown in central Mexico as explained by the first 10 principal components (PC).

\begin{tabular}{lccc}
\hline \hline PC & Eigenvalue & Proportion & Cumulative \\
\hline 1 & 8.02 & 0.286 & 0.286 \\
2 & 5.18 & 0.185 & 0.471 \\
3 & 4.37 & 0.156 & 0.630 \\
4 & 2.30 & 0.082 & 0.710 \\
5 & 1.25 & 0.044 & 0.755 \\
6 & 0.87 & 0.031 & 0.786 \\
7 & 0.83 & 0.030 & 0.815 \\
8 & 0.71 & 0.025 & 0.840 \\
9 & 0.68 & 0.024 & 0.865 \\
10 & 0.60 & 0.021 & 0.866 \\
\hline
\end{tabular}

slight thinning practiced in this study, but low fruit weight was more common in unselected populations and in cultivars with a short Fdp.

$\mathrm{Pw}$ was higher for most introduced cultivars and families when compared to the majority of local populations and selections (Table 3). This situation is expressed as a high Frw : pw, which was particularly high for the local cultivar 'Lucero' and its seedling 15 2 and for the the open pollinated seedlings of 'Neethling' and 'Kakamas' from South Africa.

Yellow-orange Co and very firm flesh were common traits in the nonmelting clingstone local accessions (Table 3).

DS was always earlier for introduced, low chilling phenotypes with a short Fdp than for others (Table 3). It may very well he that their leaves were older and/or more susceptible to rust.

Number of days required to reach $80 \%$ seed germination (D80g) and GP showed that low chilling requirement phenotypes reached $80 \%$ germination in $<50$ days, while most local populations ranged between 50 and 70 days (Table 3). The higher chilling requirement phenotypes required $>75$ days under stratification (Perez, 1990b). The germination period was short for local populations and selections $(<12$ days from the first germinated seed to $80 \%$ germination) and was relatively uniform as a result of many generations of selfing (Perez, 1990a, 1990b). However, it was long for most introduced families, reflecting their hybrid origin.

Relationships. The widest range of variability among accessions was registered for the proportion of $\% \mathrm{NOb}$, followed by the proportion of $\% \mathrm{~N} 3 \mathrm{~b}$. Firm, HS, La, number of days required by seeds to reach $80 \%$ germination under stratification (Dd80g, and BB.

Table 5. Correlations between original variables and the first three principal components (PC) as observed in 52 peach accessions in central Mexico.

\begin{tabular}{|c|c|c|c|}
\hline Variables & $\mathrm{PCl}$ & PC2 & PC3 \\
\hline Vigor & -0.68 & --- & $\cdots$ \\
\hline GH & 0.87 & --- & -- \\
\hline La & 0.88 & --- & -- \\
\hline RSp & 0.53 & --- & -.. \\
\hline RTd & -0.77 & --- & --- \\
\hline $\mathrm{Rf}$ & 0.53 & --- & 0.54 \\
\hline BB & --- & 0.62 & 0.57 \\
\hline Prec & --- & -0.61 & -.- \\
\hline $\mathrm{Bd}$ & 0.70 & --- & $--\cdot$ \\
\hline $\mathrm{B} / \mathrm{sl}$ & --- & -0.62 & --- \\
\hline $\mathrm{B} / \mathrm{n}$ & $\cdots$ & -0.66 & 0.56 \\
\hline$\% \mathrm{~N}(\mathrm{bb}$ & -- & 0.64 & --- \\
\hline$\% \mathrm{~N} 1 \mathrm{~b}$ & -- & 0.44 & -0.72 \\
\hline$\% \mathrm{~N} 2 \mathrm{~b}$ & --- & --- & 0.51 \\
\hline$\%$ N3b & --- & -0.57 & 0.57 \\
\hline $\mathrm{Fl} / \mathrm{sl}$ & --- & -0.56 & --- \\
\hline $\mathrm{Sd}$ & 0.91 & --- & $\cdots$ \\
\hline $\mathrm{P}$ & --- & -0.64 & $\cdots$ \\
\hline HS & -10.68 & 0.50 & -.- \\
\hline Fdp & -0.73 & --- & --- \\
\hline Frw & --- & --- & -- \\
\hline $\mathrm{Co}$ & $\cdots$ & --- & -- \\
\hline Firm & --- & 0.55 & --- \\
\hline Frw/pw & --- & 0.49 & -.- \\
\hline $\mathrm{Pw}$ & --- & 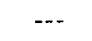 & --- \\
\hline DS & -0.74 & 0.51 & --- \\
\hline D80 $\mathrm{g}$ & --- & 0.52 & 0.63 \\
\hline $\mathrm{Gp}$ & 0.72 & $-\cdot$ & --- \\
\hline
\end{tabular}




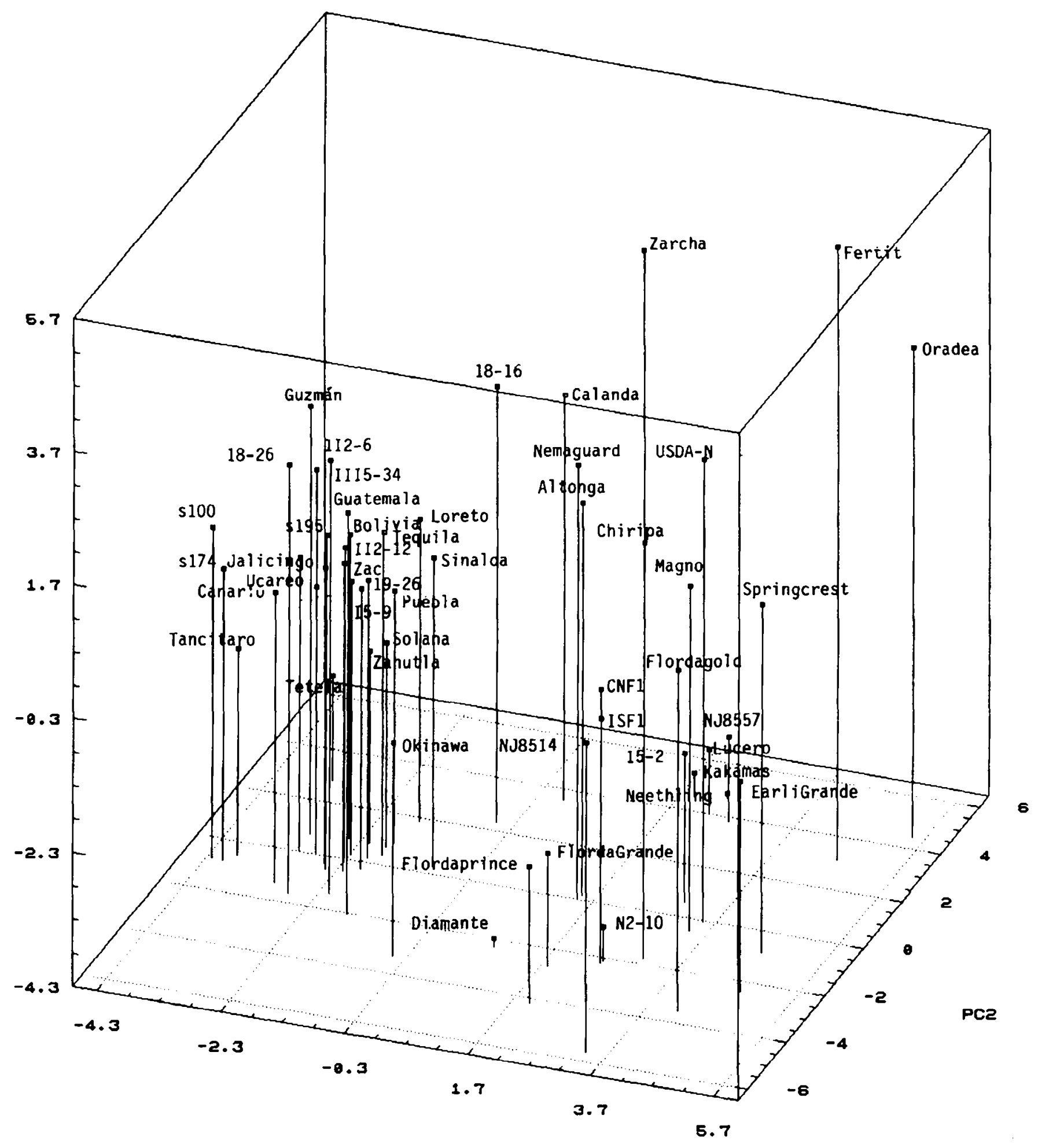

PC1

Fig. 1. Phenotypic relationships among peach cultivars, families, and populations grown in central Mexico as given by the first three principal components.

Compact $\mathrm{GH}(\mathrm{GH}=4$, Table 3) was closely linked with thicker shoots $(r=0.84)$ and larger leaves $(r=0.71)$. However, it was negatively correlated with resistance to rust $(r=-0.71)$ and defoliation period $(r=-0.71)$.

Large leaves were generally found on trees with larger buds ( $r$ $=0.62)$ and thicker shoots $(r=0.80)$.
Resistance to powdery mildew was observed mainly on trees that ripen relatively early $(r=-0.70)$ and had a short fruit development period $(r=-0.66)$.

Bud density along I -year-old shoots was positively correlated with the number of buds per node $(r=0.71)$ and with the proportion of nodes with three buds ( $r=0.64)$, and negatively correlated with 
the proportion of nodes with one bud ( $r=-0.64)$ and without buds $(r=-0.60)$. There were two opposite groups with respect to bud density and distribution: 1) trees with high bud density, which had a high percentage of nodes with three buds, and 2) trees with medium to low bud densities, which had a high proportion of nodes with one bud and without buds.

Prec, as detected during second leaf, was found to be closely associated with productivity ( $r=0.78)$.

Larger fruits (Frw) were correlated with a high fruit flesh to pit ratio $(r=0.60)$.

Generally, late ripening phenotypes were more resistant to rust ( $r=0.62)$ and retained their leaves longer $(r=0.74)$. Surprisingly, harvest season and fruit weight were not well correlated in this study, and fruit color was not found to be associated with other variables.

The number of days required by stratified seeds to reach $80 \%$ germination was associated with winter frost seedlingresistance $(r$ $=0.64)$ and with budbreak season $(r=0.73)$.

Principal component analysis (PCA). Grouping of peach phenotypes using PCA was based mainly on the first three PC that account for $63 \%$ of the variability observed (Table 4). The most important variables integrated by $\mathrm{PCl}$ were, in order of importance, Sd, La, GH, RTd, DS, GP, Bd, HS, RSp, and Rf (Table 5). All positive correlations represent traits that were more common among foreign phenotypes ( $\mathrm{sd}$, La, GH, RSp, and Bd), while negative values were associated with local populations (high vigor, RTd, longer fruit development period, and late defoliation).

PC2 accounted for $18.5 \%$ of the variability observed (Table 4) and was correlated with 13 variables, including traits related to bud characteristics such as buds per node and buds/meter, proportion of nodes without buds and proportion of nodes with three buds, and to phenology such as budbreak, harvest and defoliation season (Table 5). PC3 also integrated traits related to bud density (buds/ meter and buds per node) and distribution: (proportion of nodes with one, two, and three buds) and temperature requirements (budbreak season and days required by seeds to germinate under stratification).

Even though there was a certain degree of variability within each group, it is possible to define clusters such as the large one formed by the Mexican and other Latin American populations and selections, located toward the left side, with negative values on PC1 (Fig. 1). A small, but compact group was formed by the South African families and selections derived from them (Lucero and 15 2 ), which arc located near the base of the platform defined by the first 3 PC, and determined by the low negative values that those genotypes registered in PC3. Low chilling requirement phenotypes had high values in PC1 and low negative values in PC2 and are located in the right-front side of the platform. Evergreen peaches and related phenotypes registered the lowest values in PC1 and can be found toward the extreme left side. Brazilian cultivars were integrated in the same cluster with low to medium chilling requirement families and cultivars from the United States. reflecting a similar genetic origin or similar adaptation.

This analysis provides a comprehensive background for peach improvement in central Mexico, helping to define goals and breeding strategies, and underlines the importance for the introduction of some important traits through breeding, such as later blooming and RSp for the local traditional growing regions, and low chill-short fruit development period, for the frost free regions located at lower elevations.

\section{Literature Cited}

Bellini, E. and F. Scaramuzzi. 1976. Monografia delle principali cultivar di pesco. vol. 11. Consiglio Nazionale delle Ricerche. Firenze, 1976.

Calahan, A., R. Scorza, P. Morgens, S. Manti, J. Cordts, and R. Cohen. 1991. Breeding for cold hardiness: Searching for genes to improve fruit quality in cold-hardy peach germplasm. HortScience 26:522-526.

Crisci, J.V. and A. López. 1983. Introducción a la teoría y practica de la taxonomía numérica. OEA-Programa Regional de Desarrollo Cientlfico y Tecnologla, Washington, DC.

Della Strada, G., C. Fideghelli, A. Liverabi, and F. Monastra. 1984. Monografia di cultivar di pesco da consumo fresco. vols. I and II, MAFISF, Rome.

Diaz, D.M., J.J. Martinez. and W. Sherman. 1986. Apple and peach production in warm climates in northwest Mexico. Fruit Var. J. 40:121125.

Fideghelli, C., G. Della Strada, F. Grassi. 1991. L'apporto del meglioramento genetico per il rinnovamento varietale del pesco. Frutticoltura 6:5-11.

Hough, L.F. 1985. Perspectives for peach breeding for the cultivars for 2000 AD. Acta Hort. 173:11-20.

Hilling, K.W. and A. Iezzoni. 1988. Multivariate analysis in a sour cherry germplasm collection. J. Amer. Soc. Hort. Sci. 113:928-934.

Iezzoni, A.F. and M.P. Pritts. 1991. Applications of principal component analysis to horticultural research. HortScience 26:334-338.

Martin, G.B. and M.N. Adams. 1987. Landraces of Phaseolus vulgaris (Fabaceae) in Northern Malawi, I. Regional variation. Econ. Botany, 41:190-203.

Monet, R. 1988. Peach and nectarine breeding situation in France, p. 184185. In: N.F. Childers and W.B. Sherman (eds.). The peach. Hort. Publ., Gainesville, Fla.

Montez, S. 1989. Evaluación de los efectos de domesticación sobre cl tomate (Physalis philadelphica Lam.) MS Thesis, Colegio de Postgraduados, Chapingo, Mexico.

Okie, W.R., D.W. Ramming, and R. Scorza. 1985. Peach, nectarine and other stone fruit breeding by the USDA in the last two decades. HortScience 20:633-641.

Pérez, G.S. 1989. El cultivo del melocotoncro en México. Frut III: 157-161.

Pérez, G.S. 1990a. Evaluación de variedades de duraznero reproducibles por semilla. Symposio CONCYTEQ-1990, Querétaro, 2.5 to 28 Sept. 1990.

Pérez, G.S. 1990b. Relationship between parental blossom season and speed of seed germination in peach. HortScience 25:958-960.

Pérez, G.S. 1992a. Associations among morphological and phenological characters representing apricot germplasm in central Mexico. J. Amer. Soc. Hort. Sci. 117:486-490.

Pérez, G.S. 1992b. Componentes de rendimiento en duraznero. Revista de Investigación, Univ Autóinoma de Querétaro 12:8-15.

Scorza, R. 1985. The development of cold hardy, disease, and insect resistant peach cultivars. Pennsylvania Fruit News 64:47-49.

Scorza, R., S.A. Mehlenbacher, and G.W. Lightner. 1985. Inbreeding and coancestry of freestone peach cultivars of the Eastern United States and implications for peach germplasm improvement. J. Amer. Soc. Hort. Sci. 110:547-557.

Scorza, R. and W.R. Okie. 1990. Peaches, p. 175-23 I. In: J.N. Moore and J.R. Ballington Jr (eds.). Genetic resources of temperate fruit and nut crops. Acta Hort. Int. Soc. Hort. Sci. Wageningen, Holland

Scorza, R., W.B. Sherman, and G.W. Lightner. 1988. Inbreeding and coancestry of low chill-short fruit development period freestone peaches and nectarines produced by the University of Florida breeding program. Fruit Var. J. 42:79-85. 